\title{
Geographically Weighted Regression and Secondary Variables for Mapping of Meteorological Data
}

\author{
Ismail Bulent Gundogdu \\ Department of Geomatics Engineering, Selcuk University, Konya 42100, Turkey
}

\begin{abstract}
GA (geostatistical analyst) is an indispensable tool to analyze various and plenty of data in GIS (geographic information system). Spatial distribution is the most effective factor for predicting of meteorological maps at the point of performance or reliability of the model. Generally, classical interpolation methods may not be sufficient to produce accurate maps. GA is more considerable in this state. Secondary variables affect the precious of prediction models especially meteorological data mapping. In this study 245 meteorological data stations have been evaluated to produce precipitation model maps in Turkey. Long term (25 years) mean annual and monthly precipitation data from Turkish State Meteorological Service and elevation, slope and aspect values from DEM (Digital Elevation Model) were registered. OK (Ordinary Kriging), OCK (Ordinary Co-Kriging) and GWR (Geographically Weighted Regression) have been used as a method to compare the models. With the study if there are effects of secondary variables to precipitation models have been illustrated on the prediction maps. Besides comparing statistical values, regional effects of secondary variables have been determined and illustrated on the maps numerically. As a result to define precipitation distribution spatially $R^{2}$ values between measured and predicted values have been calculated 0.55 for Kriging, 0.67 for OCK and 0.86 for GWR. Cross validation indicated that GWR interpolation yields the smallest prediction error with elevation, slope and aspect. Spatial distribution of meteorological stations is also other important factor for similar studies.
\end{abstract}

Key words: Geostatistical analyst, precipitation map, ordinary Co-Kriging, geographically weighted regression, meteorological data.

\section{Introduction}

According to Turkish meteorologist severe unpredicted rainy days will be existed after severe hot climatic conditions, and the days will be existed frequently in future 5 years. At the scenario of future Turkey climate, aridity will be threatened to the south regions and torrents to the north regions. So it is the most important subject precision of precipitation maps performance must be increased with other effective factors.

GA (geostatistical analyst) is one of the most effective methods to analyse discrete data points in space both predict an unmeasured points' spatial positions and produce prediction maps. GA is able to not only produce prediction or probability maps but also examine the precision of different models. GA

Corresponding author: Ismail Bulent Gundogdu, Ph.D., associate professor, research fields: Cartography, GIS, Geostatistical analyst, Delphi programming, and Image proccessing. Email: bgundogdu@ selcuk.edu.tr. has proved to be popular in many areas such as agriculture, hydrology, ecology, natural resource models, mining, geology, environmental science, building, cartography, risk management, and so on. The objective problem is to make a prediction at an unsampled location for a variable based on its relationship with one or more secondary variables. Several geostatistical data integration methods are available, and the choice depends on the type of the data available and the purpose of the study.

Briefly, the geostatistical method is a four-step procedure that calls on several geostatistical tools. These steps are: learn from the data through simple statistical analysis, find relationships between the data sets through cross plots, use what has been learned and found in the data to determine the spatial distribution of control points, and, finally, assess the accuracy/error/risk of the map using conditional simulation [1]. 
According to Goovaerts and Burrough [2, 3], a geostatistical approach is more effective because it has the advantage of using spatial context and external information as a random quantity in order to determine the change of scale most appropriate and possibly to improve the predictions or simulations required.

Perry and Hollis [4] indicate in their study that climate data are often strongly related to topographic and geographic variables, and it is important to incorporate these factors.

Some recent studies have used topographical elevation as a source of secondary information to hydro meteorological variables, as referred to by Goovaerts [2, 5], Deirasme et al. [6], Gomez-Hernandez and Cassigara [7] and Diodato and Ceccarelli [8]. Several authors have shown the superiority of the GA methods over the conventional methods for estimation of rainfall at un-gauged locations with different secondary variables, with altitude [9], with slope, aspect, distance to nearest river and solar radiation [10-14], besides elevation.

Kriging methods have been used in some different areas for example, they have been used for modelling the spatial variability of tropical rainforest soils [15], soil mapping [16, 17], modelling the spatial distribution of human diseases [18], water table data mapping $[19,20]$, mapping the abundance of fish in the ocean [21], rainfall mapping [22], and for detailed mathematical approaches [23].

In recent years, a simple but powerful technique called GWR (Geographically Weighted Regression) has been developed to explore the spatially varying relationships and to account for spatial autocorrelation [24]. This technique has been applied in some ecology [25], social [26], and urban studies [27], regional development [27], population segregation [28], the rainfall-altitude relationship [29], relation between elevation and monthly precipitation amount is illustrated by Lloyd [22], Brunsdon et al. [29], Gundogdu [30], Okwuashi [31], Taghipour [32, 33]
Xu et al. (2015), regional analysis [34], land use and water quality [35], water consumption [36].

It is important to compare the statistical results obtained using alternative methods and different secondary variables applied to the same dataset or area, because no single method or always the same secondary variable(s) is optimal for all regions or all seasons. For estimating long-year-average annual and monthly precipitation in Turkey, GWR has been compared with two alternative methods: OK (Ordinary Kriging), and OCK (Ordinary Co-Kriging). It is concluded that GWR has proved a robust and flexible interpolation method because it can also take into account auxiliary information in the form of smoothing the DEM (Digital Elevation Model) besides secondary variable values.

\section{Study Area and Methods}

Continental climate conditions are effective in the area. In severe winter days soil freezes as $50 \mathrm{~cm}$ depth. Because of the loosen soil after warm days, precipitation becomes the most important factor for erosion and controlling of environmental changing. Mean annual precipitation is $720 \mathrm{~mm}$ and maximum difference of elevation is $2,500 \mathrm{~m}$ in the area. Precipitation records of 245 meteorological stations' data for 25 years have been obtained from Turkish State Meteorological Service and input into the database using Ms Access to set up the GIS (geographical information systems)-based application. In this process besides all monthly and mean annual precipitation values, times, elevation, slope and aspects values were recorded in the main dataset. DEM $(25 \mathrm{~m} \times 25 \mathrm{~m})$ has been used to get values of secondary variables. All computations have been performed using the Geostatistical Analyst which was integrated into ArcGIS 10.0-ESRI software. Fig. 1 shows the study area and network of stations.

For estimating 25-year-average annual and monthly precipitation in the area, data have been controlled by histogram values if there is necessary transformation 
than GWR, Kriging and OCK surfaces have been compared each other.

\subsection{Kriging Interpolation}

Kriging takes into consideration weights of the surrounding measured values to derive a prediction for an unmeasured location. The technique has proved to be popular in many areas such as agriculture, mining, geology, environmental science, building, cartography, risk management, and so on.

Calculating the variance is the most important and distinctive peculiarity of Kriging in comparison with other techniques. The value is the criterion for the reliability of the estimated value. If the calculated variance is smaller than the variance of certain values, the estimated value is reliable for the unsampled point or area. Kriging method is based on the autocorrelation of a variable between two points that is formulated as Eq. (1):

$$
Z(s)=\mu+\varepsilon(s)
$$

$Z(s)$ consists of two parts: a deterministic trend $\mu(s)$ (i.e. flow direction) and a random auto correlated error $\varepsilon(s)$. The symbol $s$ simply indicates the location of a point. Because $\mu(s)$ is a deterministic trend, the selection of a Kriging method is based on whether a directional trend exists or not.

The ordinary Kriging formula is generally given by Eq. (2):

$$
Z^{*}(u)=\sum_{a=1}^{n(u)} \lambda_{a}(u) Z\left(u_{a}\right)+\left[1-\sum_{a=1}^{n(u)} \lambda_{a}(u)\right] m
$$

where, $Z^{*}(u)$ is the ordinary Kriging estimate at spatial location $u, n(u)$ is the number of the data used at the known locations given a neighbourhood, $Z\left(u_{a}\right)$ are the $n$ measured data at locations $u_{a}$ located close to $u, m$ is mean of distribution, $\lambda_{a}(u)=$ weights for location $u_{a}$ computed from the spatial covariance matrix based on the spatial continuity (variogram) model, which is given by Eq. (3):

$$
\lambda(h)=\frac{1}{2 n} \sum_{i=1}^{n}\left(z\left(u_{i}\right)-z\left(u_{i}+b\right)\right)^{2}
$$

where, $n$ is the number of data pairs separated by distance $b, z\left(u_{i}\right)$ and $z\left(u_{i}+b\right)$ are the data values at locations separated by distance $b$.

\subsection{The Multivariate Geostatistical Approach}

Geostatistical procedures, known as Kriging, start from recognizing that spatial variation of any continuous attribute is often too irregular to be modelled by one simple, smooth mathematical function. On the contrary, variation can be better described by a stochastic surface. Each measurement $z(s)$ is thus interpreted as a particular realization of a random variable $Z(s)$ and Kriging is a generic name adopted by the geostatisticians fora family of local

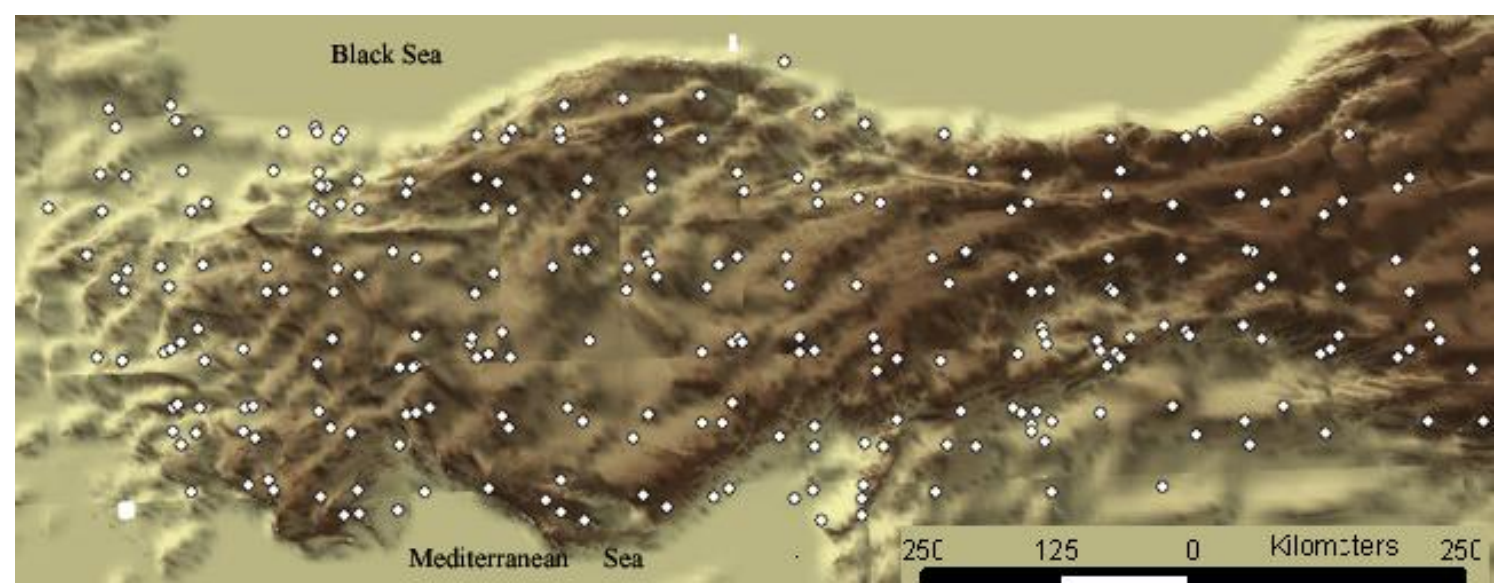

Fig. 1 Spatial distribution of $\mathbf{2 4 5}$ meteorological stations. 
least-squares regression algorithms. The basic idea is to estimate the unknown rainfall value at the unsampled location $s$ as a linear combination of same neighbouring observations. A kriged estimate of the variable at location $s_{0}$ is given by Eq. (4):

$$
Z_{O C K}\left(s_{0}\right)=\sum_{i=1}^{n} \lambda_{i} z_{i}\left(s_{i}\right)+\sum_{j=1}^{m} \lambda_{j} z_{2}\left(s_{j}\right)
$$

where $z_{i}$ is a vector of the observed primary data (in our case corresponding to precipitation) selected in the $s_{0}$ neighbourhood observation $s_{i}, z_{2}$ is a vector of the observed secondary data (in our case corresponding to elevation) selected in the $s_{0}$ neighbourhood observation $s_{j}, \lambda_{i}$ and $\lambda_{j}$ are weights associated with the distance $h_{0(i)}$ (between $s_{0}$ and $s_{i}$ ) and $h_{0(j)}$ (between $s_{0}$ and $s_{i}$ ), respectively, calculated during the solution of the Kriging simultaneous equation system $[8,37]$.

\subsection{Geographically Weighted Regression}

GWR is thus a newly developed statistical methodology that extends an ordinary linear regression model by allowing estimation of local, rather than global, parameters. Coefficients are specific to location $i$, rather than assumed to be constant. The calibration of the GWR model relies on a sequence of locally linear regressions to produce estimates for each point in space by using weighted subsamples of data information from nearby observations. For each observation $i$, the model computes a matrix of weights in which the largest values are assigned to the corresponding nearest observations of $i$.

Geographically weighted regression is used to estimate locally linear coefficients and the dependent variable. The GWR model is formally defined as Eq. (5):

$$
P_{i}=\beta_{o i}+\sum_{k} \beta_{k i} X_{k i}+\varepsilon_{i}
$$

where $P_{i}$ is the $i$ th observation of the dependent variable. $X_{k i}$ is the $i$ th observation of the $k$ th independent variable, $\varepsilon_{i}$ is the $i$ th value of a normally distributed error vector with mean equal to zero, $\beta_{k i}$ is the constant estimated for local regression $i$, and $\beta_{k i}$ is the regression coefficient estimated for regression $i$ and variable $k$. This differs from ordinary least squares regression by utilizing distinct constants and regression parameters for each point, rather than a single set of global parameters. The estimation algorithm essentially iterates through $n$ weighted least square regression, each one modified by a unique distance-decay weight matrix. Estimation for point $i$ thus takes the form shown in Eq. (6):

$$
B_{i}=\left(X^{T} W_{i} X\right)^{-1} X^{T} W_{i} P
$$

where $B_{i}$ is the vector of estimated coefficients for observations, $P$ is the vector of observed dependent variables, $\mathrm{X}$ is the $n \times k$ matrix of explanatory variables, and $W_{i}$ is a diagonal distance-decay weight matrix specific to $i$ 's location relative to the surrounding observations [24].

\section{Assessment of Data}

Table 1 shows general statistical information of data. These values must be controlled if these are normal distribution before geostatistical application. If the mean and median values are close, it can be said that the data have a normal distribution. Normal distribution of data can be realised with a skewness value close to one. According to the values in Table 1, the data are normally distributed. However, a normal QQPlot also allows us to compare the data with a normal distribution.

Initially, all data must be controlled if it is in normal distribution or not. Ideally, it must be in normal distribution or symmetrical. A histogram shows whether distributions of data are symmetrical or not. Fig. 2 shows the frequency distributions of data. However, the secondary variable's distributions are symmetric, but precipitation distributions draw away a little from normality, as it also results from skewness. 
Table 1 Statistical values to describe mean annual precipitation, elevation, aspect and slope.

\begin{tabular}{lllll}
\hline Statistics & Mean annual precipitation $(\mathrm{cm})$ & Elevation $(\mathrm{m})$ & Aspect & Slope \\
\hline Min value & 2.00 & 1.68 & 1 & 2 \\
Max value & 16.41 & 2,400 & 356 & 93 \\
Mean value & 7.17 & 776.11 & 194.41 & 79.12 \\
Std. dev. & 2.41 & 582.50 & 11.00 & 20.23 \\
Skewness & 1.21 & 0.978 & 0.967 & 1.03 \\
Kurtosis & 3.34 & 2.46 & 2 & 5.09 \\
$1^{\text {st }}$ quartile & 4.07 & 7.62 & 121.09 & 73.88 \\
Median value & 4.31 & 774 & 194 & 83 \\
$3^{\text {rd }}$ quartile & 7.44 & $1,111.4$ & 281.34 & 82 \\
\hline
\end{tabular}

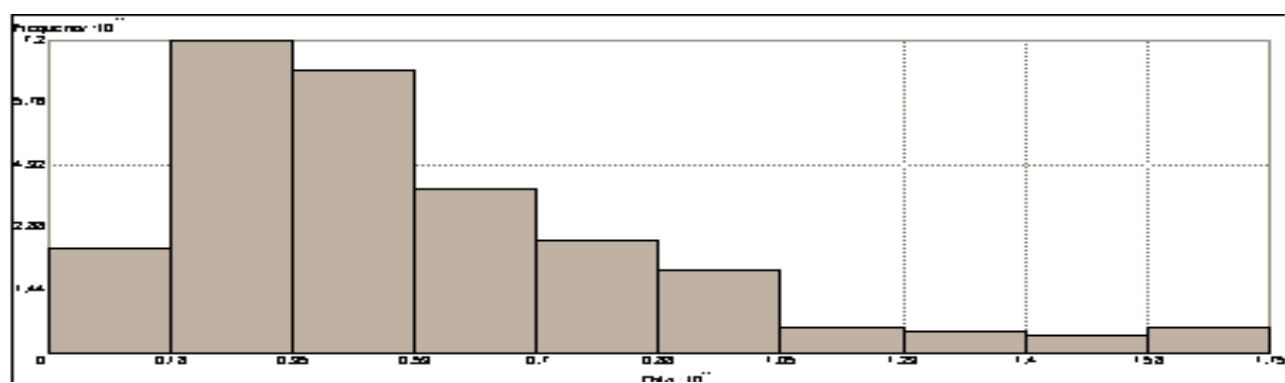

(a)

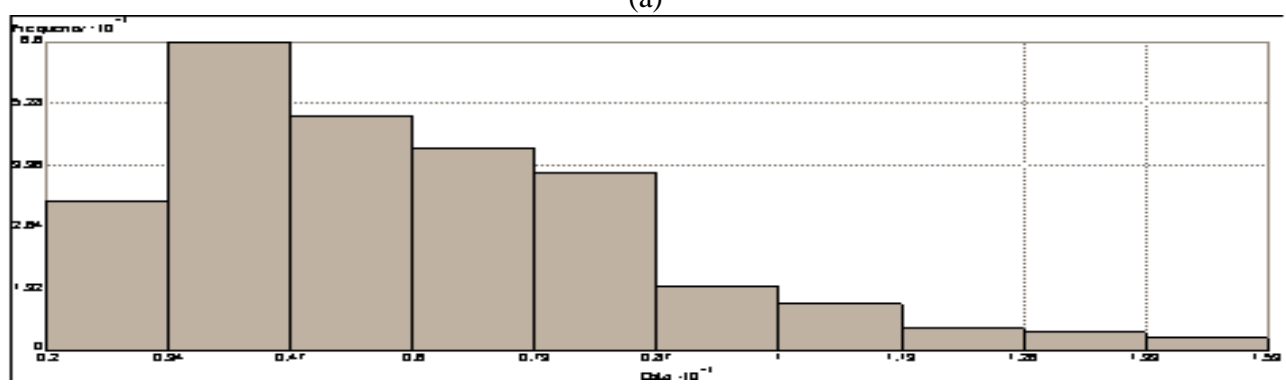

(b)

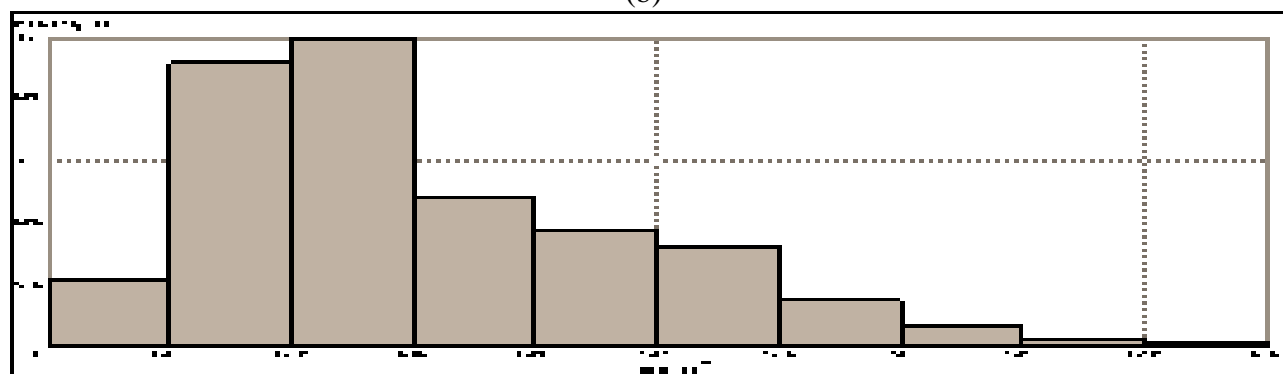

(c)

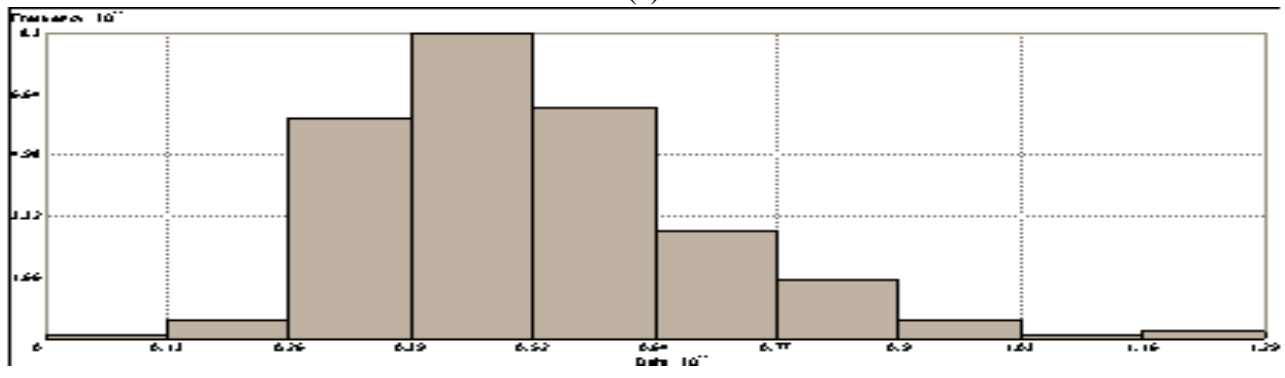

(d)

Fig. 2 Histogram for the annual precipitation (a), aspect (b), elevation (c) and slope data (d). 
Therefore, it was decided to work on data not transformed, which would not affect the estimate of the process.

\subsection{Interpolator Performance}

Generally, the best model is the one that has the standardized mean nearest to zero, the smallest root-mean-square prediction error, the average standard error nearest the root-mean-square prediction error, and the standardized root-mean-square prediction error nearest the one [37]. The best statistical results in $\mathrm{GWR}_{\mathrm{EAS}}$ column are shown at the Table 2.

Fig. 3 shows semivariances (a) with $\mathrm{OK}$, (b) with OCK and (c) with GWR. Ideally the value of the semivariogram for precipitation should be zero when the separation vector is zero. Since measurement error exists this is not true in the study. In this case Diodato and Ceccarelli [8] declared that it could be assumed that the phenomenon to be estimated was smooth (i.e. annual precipitation values changed gradually with the distance). In this respect the exponential semivariogram for precipitation with small nugget effect and cross-covariance function was selected as the base model for calculations.

In this phase, absolute error values were reestimated using seasonal precipitation (Table 3 ) for controlling accommodation between yearly and seasonal values.

The influence of the topographic conditions is essentially sensitive on mean, root mean square and average standard errors. Root mean square is close to the average standard errors mean correctly assessing the variability in prediction. There is clearly a significant improvement in the estimation performance when taking into account $E A S$ as a secondary variable through GWR: The mean absolute error decreases from 3.97 to $0.11 \mathrm{~cm}$.

\section{Result Maps and Conclusions}

The aims of this study are modeling precipitation distribution by using spatial relationship between precipitation and secondary variables, and defining effects of secondary variables on modeling performance of precipitation. Taking into account the effect of geographic and topographic factors such as elevation, aspect, and slope can usually give better results in defining the spatial distribution of precipitation. Before mapping of precipitation, all measured and predicted $R^{2}$ values have been shown in Fig. 4. The diagrams show correlations of measured and predicted values.

The techniques were illustrated by using annual and monthly precipitation observations collected at 245 climatic stations in Turkey. In the case study, cross-validation was used to compare the prediction performances of the three methods. GWR $\mathrm{EAS}_{\mathrm{EAs}}$ gave the best performance in the statistical sense. According to Table 2, when comparing three methods' statistical error values $\mathrm{GWR}_{\mathrm{EAS}}$ yields the mean error nearest to zero, and RMSS nearest to 1. For result maps in Fig. 5, 3 types of maps were produced to compare the precipitation distribution visually with 3 methods. In Fig. 5 (a); (b); (c), maps show effective rainy regions in the area. After decision that GWR is the best method for precipitation modelling, secondary variables were used one by one and two by two and trio (Elevation, aspect, slope, elevation-aspect, elevation-slope, aspect-slope and elevation-aspect-slope).

Table 2 Statistics of the experimental errors computed from mean annual precipitation data (Kriging, OCK (EAS): Ordinary Co-Kriging with elevation, aspect and slope, GWR with elevation (E), aspect (A), slope (S), elevation-aspe ct (EA), elevation-slope (ES), aspect-slope (AS), elevation-aspect-slope (EAS)).

\begin{tabular}{llllllllll}
\hline & Kriging & OCK (EAS) & GWR (E) & GWR (A) & GWR (S) & GWR (EA) & GWR (ES) & GWR (AS) & GWR EAS \\
\hline Mean & 0.19188 & -0.00102 & -0.00190 & -0.00206 & 0.00825 & -0.00640 & 0.03173 & 0.00993 & 0.00046 \\
RMS & 1.85300 & 1.12600 & 1.19600 & 1.50400 & 1.54140 & 1.23300 & 1.48300 & 0.71170 & 1.12000 \\
RMSS & 0.98880 & 0.75610 & 1.03200 & 1.15400 & 1.18600 & 1.01500 & 1.06400 & 1.42200 & 1.04400 \\
$T$ Test & 0.03044 & 2.65322 & 0.02717 & 0.02746 & 0.10502 & 0.02848 & 0.02333 & 0.08348 & 0.00655 \\
\hline
\end{tabular}




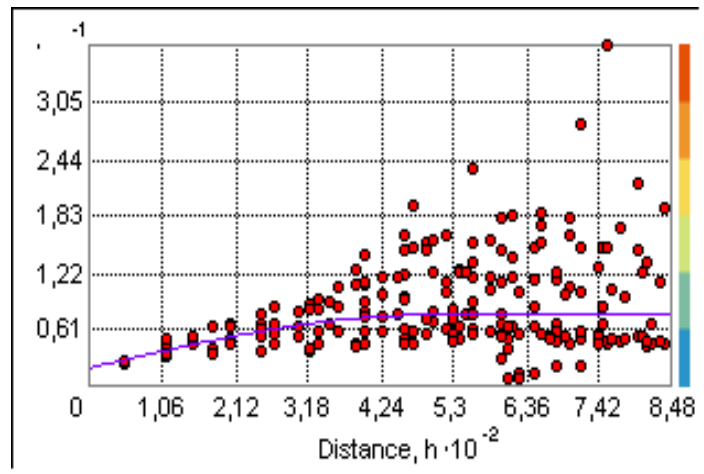

(a)

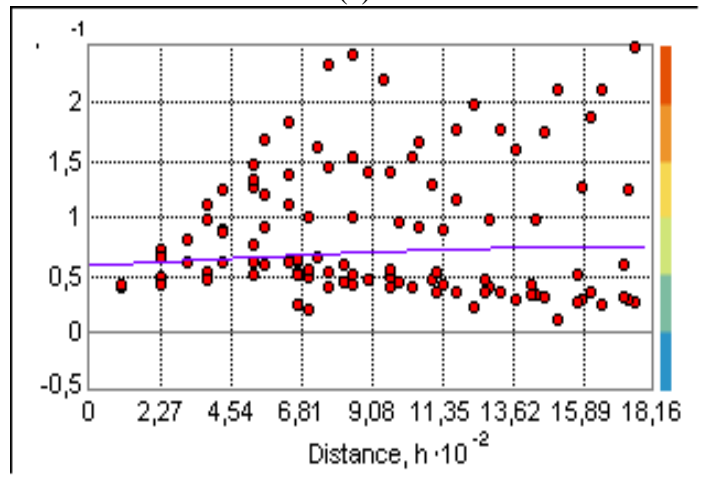

(b)

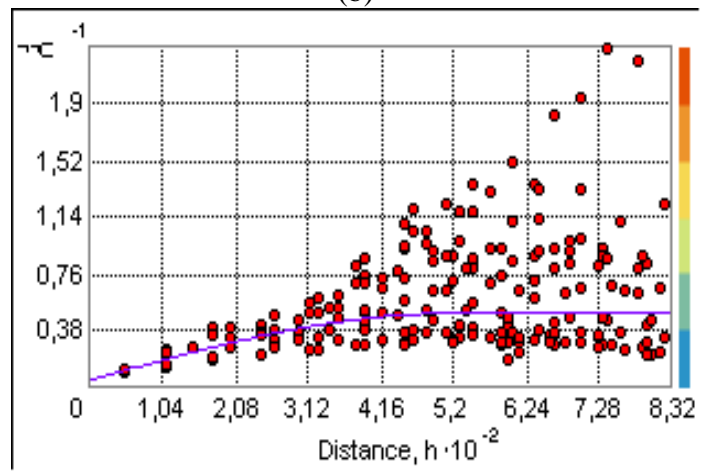

(c)

Fig. 3 Experimental semivariance and their coregionali zation model (continuous line) for (a) Kriging, (b) OC $\mathrm{K}_{\mathrm{EAS}}$ and (c) GWR EAS.

Table 3 Mean absolute error prediction (cm) compute d from seasonal precipitation data.

\begin{tabular}{lllll}
\hline Algorithms & Spring & Summer & Autumn & Winter \\
\hline Kriging & 3.127 & 3.166 & 3.666 & 3.927 \\
OCK $_{\text {EAS }}$ & 2.173 & 2.228 & 2.185 & 2.733 \\
GWR $_{\text {EAS }}$ & 0.141 & 0.150 & 0.443 & 0.110 \\
\hline
\end{tabular}

The $R^{2}$ maps of secondary variables can be produced by GWR results Tables 2 and 3. Fig. 5 (d); (e); (f) maps show high and low regression values distribution on the maps. The maps show that points are affected to model in which quantity at the side of secondary variables. It also indicates the more priority regions to take precautions for water erosion. Indeed, the spatial distribution of station points and the number of them is also effective to the performance of the precipitation models.

Turkey has been effected by cold air mass from north and warm air mass from south at side of geographical location. Since the area is in centre climatic zone, four seasons have been existed explicitly. However the area has taken part in the warm climatic zone, it has some different climatic properties. The reasons of these differences are: to be surrounded with seas at 3 sides, to be lied parallel mountains to seasides, prevented sea effects to interior area because of mountains, increasing elevation from west to east.

Actually $\mathrm{OCK}_{\mathrm{EAS}}$ and $\mathrm{GWR}_{\mathrm{EAS}}$ have approximate errors values; $\mathrm{GWR}_{\mathrm{EAS}}$ yields more reliable and small

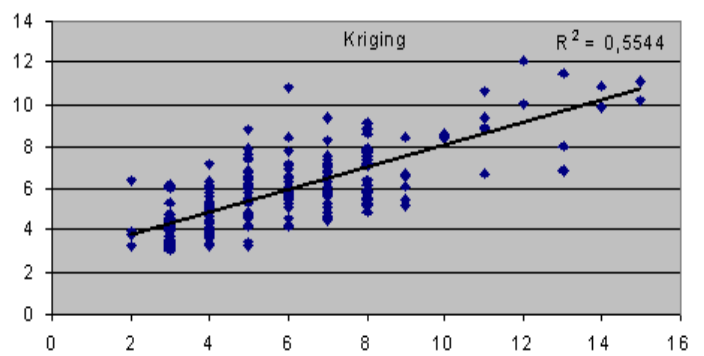

(a)

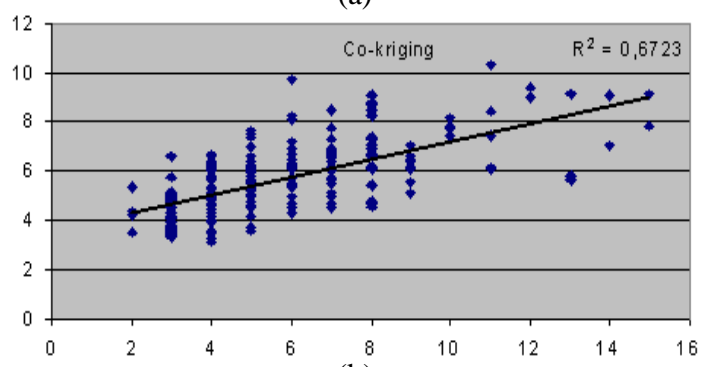

(b)

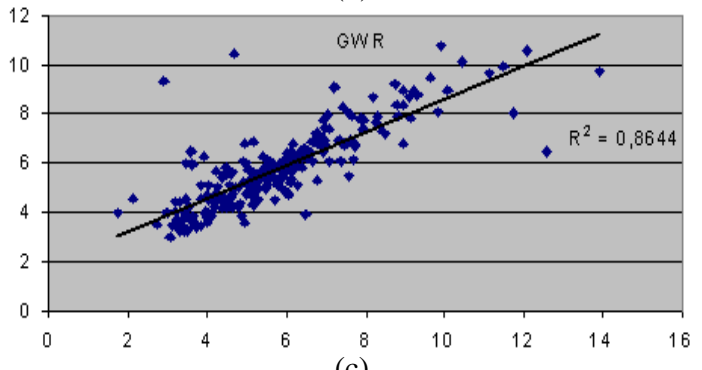

(c)

Fig. 4 Measured and predicted correlation graphics (a) with OK, (b) with OCK, (c) with GWR. 


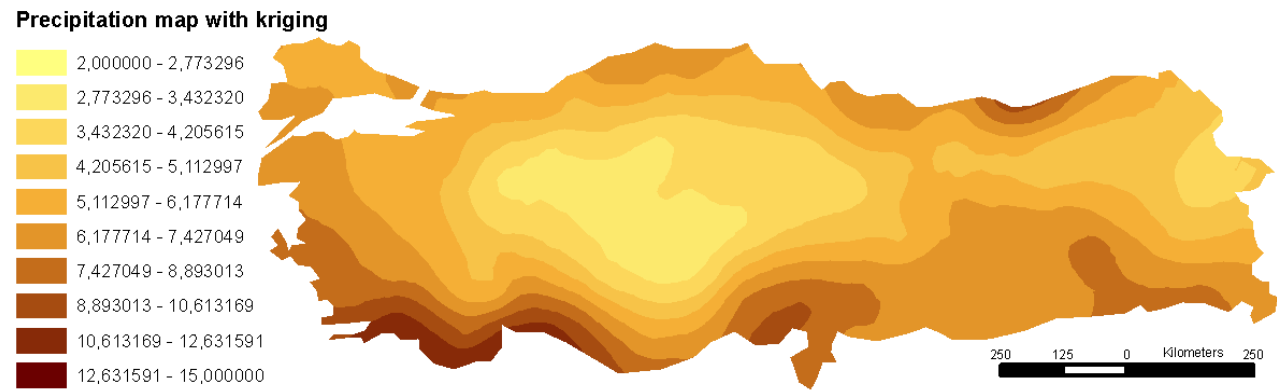

(a)

Precipitation map with Cokriging

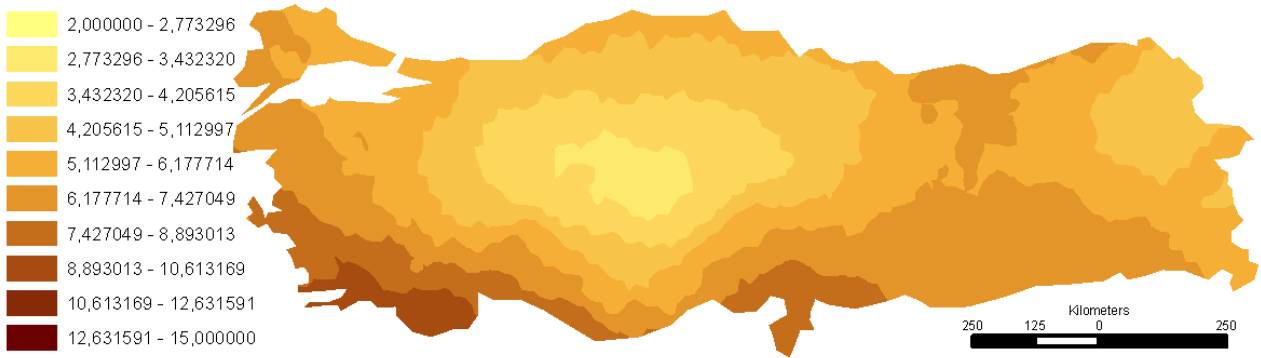

(b)

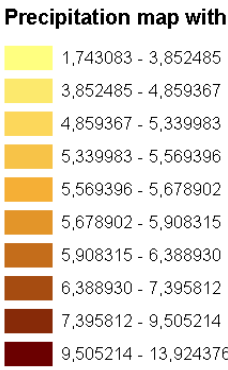

Slope effects

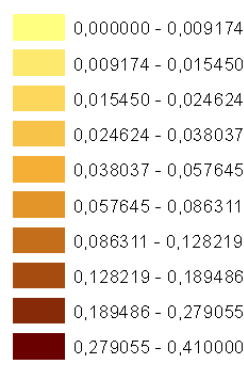

Aspect effects

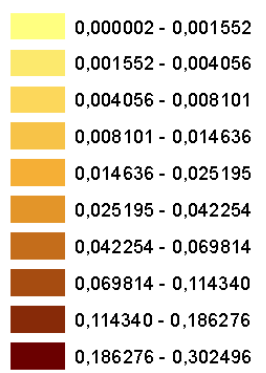

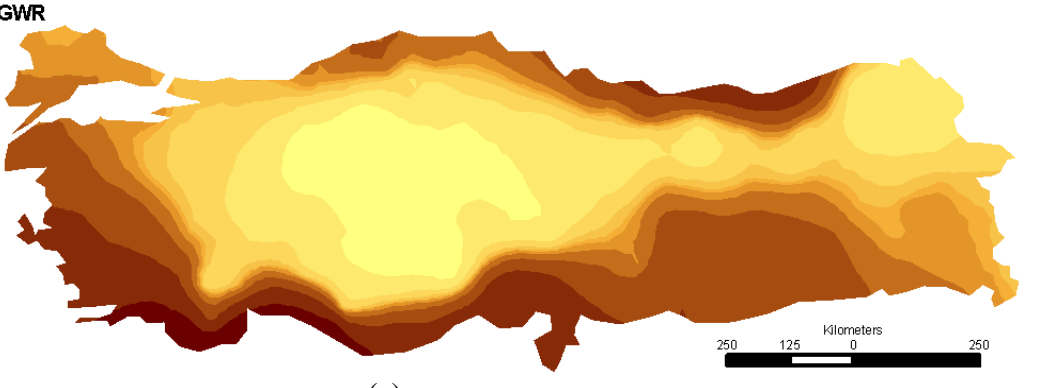

(c)

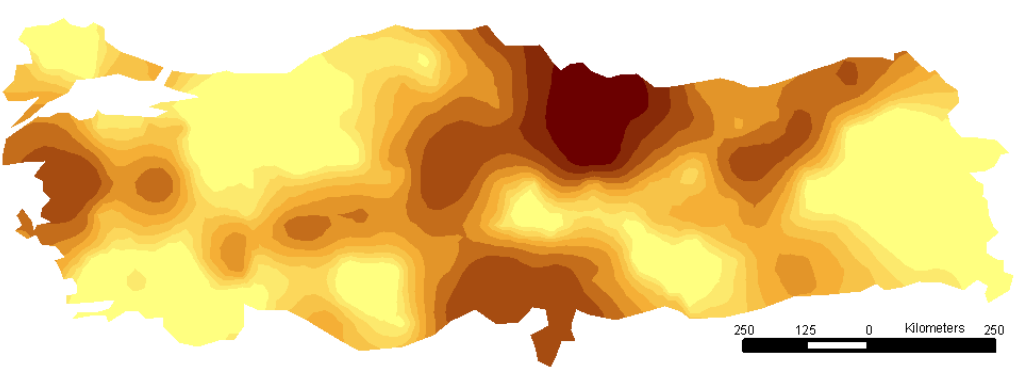

(d)

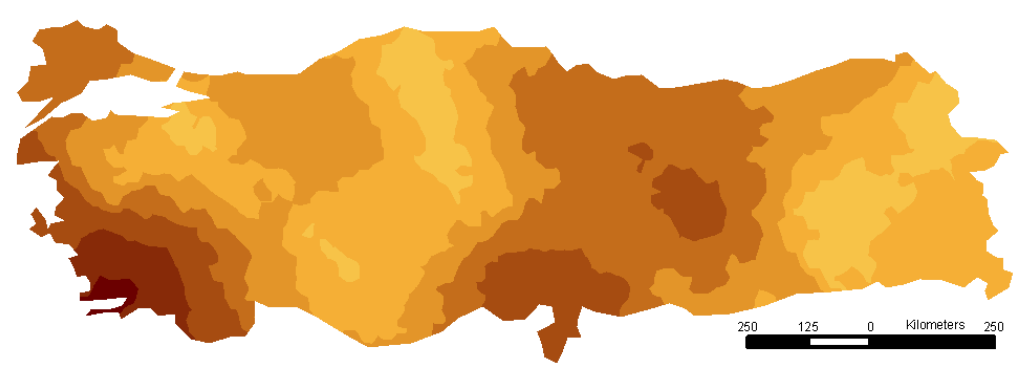

(e) 

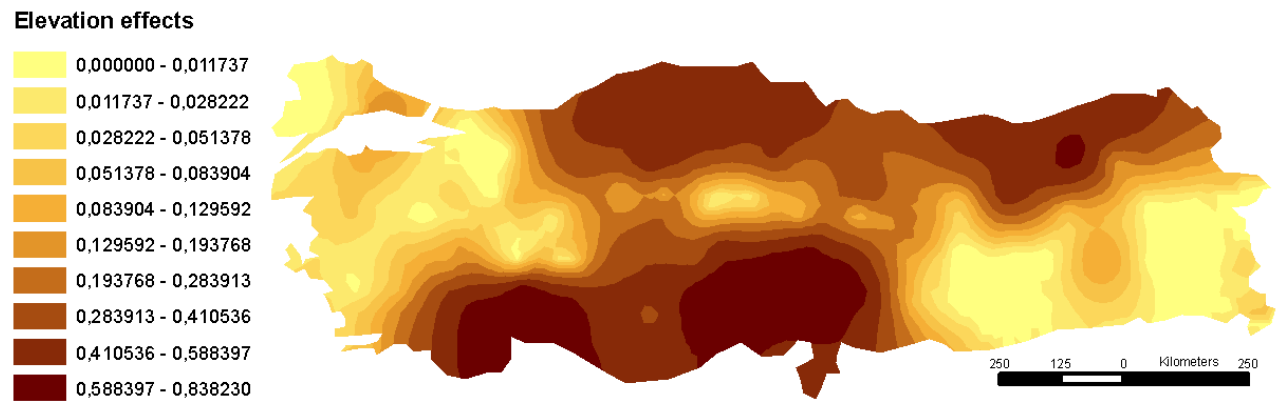

(f)

Fig. 5 (a) Precipitation maps with $\mathrm{OK}$, (b) with $\mathrm{COK}_{\mathrm{EAS}}$, (c) with $\mathrm{GWR}_{\mathrm{EAS}}$, (d) $\mathrm{R}^{2}$ value distribution with slope, (e) $\mathbf{R}^{2}$ aspect, (f) $\mathbf{R}^{2}$ with elevation values [30].

prediction error values particularly in the seasonal evaluation.

As a result, Ordinary Kriging is not able to use secondary variables. A recently developed technique, GWR, is used to examine the relationships between precipitation and other secondary variables. The results of the study suggest that GWR technique has abilities to evaluate which secondary variable is more effective in the area for each point. Elevation effects on the north and south sea sides can be observed easily. According to result maps influence of slope is more effective on middle-north region. Aspect degree is more effective on south-west region. Some urgent precautions must be in agenda for these regions.

\section{Acknowledgement}

This study has been re-worked and developed from Gundogdu and Esen [30].

\section{References}

[1] Kok, M. V., and Ulker, B. 2008. "Reserve Estimation Using Geostatistics." Energy Source Part A Recovery Utilization and Environmental Effects 30 (2): 93-100.

[2] Goovaerts, P. 2000. "Geostatistical Approaches for Incorporating Elevation into the Spatial Interpolation of Rainfall." Journal of Hydrology 228 (1-2): 113-29.

[3] Burrough, P. A. 2001. "GIS and Geostatistics: Essential Partners for Spatial Analysis." Environmental and Ecolopical Statistics 8: 361-77.

[4] Perry, M., and Hollis, D. 2005. "The Generation of Monthly Gridded Datasets for a Range of Climatic Variables over the UK." International Journal of Climatology: 1041-54.

[5] Goovaerts, P. 1999. "Using Elevation to Aid the
Geostatistical Mapping of Rainfall Erosivity." Catena 34: 227-42.

[6] Deirasme, J., Humbert, J., Drogue, G., and Freslon, N. 2001. "Geostatistical Interpolation of Rainfall in Mountainous Areas." In Proceedings of Meeting GeoENV III-Geostatistics for Environmental Applications, 57-66.

[7] Gomez-Hernandez, J. J., and Cassiraga, E. F. 2001. "Incorporating Information from a Digital Elevation Model for Improving the Areal Estimation of Rainfall." In Proceedings of Meeting GeoENV III-Geostatistics for Environmental Application, 67-78.

[8] Diodato, N., and Ceccarelli, M. 2005. "Interpolation Processes Using Multivariate Geostatistics for Mapping of Climatological Precipitation Mean in the Sannio Mountains (Southern Italy)." Earth Surface Processes and Landforms 259-68.

[9] Guler, M., Cemek, B., and Gunal, H. 2007. “Assesment of Some Spatial Climatic Layers though GIS and Statistical Analysis Techniques in Samsun Turkey." Meteorological Applications 14: 163-69.

[10] Erxleben, J., Elder, K., and Davia, R. 2002. "Comparision of Spatial Interpolation Methods for Estimating Snow Distribution in the Colorado Rock Mountains." Hydrological Processes 16: 3627-49.

[11] Bostan, P. A., and Akyurek, Z. 2007. Spatial Modelling of the Mean Annual Precipitation of Turkey by Using Secondary Variables. Trabzon.

[12] Akhtari, R., Morid, S., Mahdian, M. H., and Smakhtin, V. 2009. "Assessment of Areal Interpolation Methods for Spatial Analysis of SPI and EDI Drought Indices." International Journal of Climatology 135-45.

[13] Gundogdu, I. B. 2014. "Interpolation Processes for Mapping of Climatological Precipitation to Investigate Water Erosion by Multivariate Geostatistics." Natural Changes 1 (2): 12-6.

[14] Gundogdu, I. B. 2014. "Multivariate Statistics for Mapping of Meteorological Precipitation." Global Journal of Engineering Science and Research Management (1-6): 20-5. 
[15] Yemefack, M., Rossiter, D. G., and Njomgang, R. 2005. "Multiscale Characterization of Soil Variability within an Agricultural Landscape Mosaic System in Cameroon." Geoderma 125 (1-2): 117-43.

[16] Leopold, U., Heuvelink, G. B., Tiktak, A., Finke, P. A., and Schoumans, O. 2005. "Accounting for Change of Support in Spatial Accuracy Assessment of Modelled Soil Mineral Phosphorous Concentration." Geoderma 130 (3-4): 368-86.

[17] Lopez-Granodos, F., Jurado-Exposito, M., Pena-Barragan, C., and Garcia-Torres, L. 2005. "Using Geostatistical and Remote Sensing Approaches for Mapping Soil Properties." European Journal of Agronomy 23 (33): 279-89.

[18] Pleydell, D. R. J., Rasul, F., Tourneux, F., Danson, F. M., Graham, A. J., Craig, P. S., and Giraudoux, P. 2004. "Modelling the Spatial Distribution of Echinococcus Multilocularis Infection in Foxes." Acta Tropica 91 (3): 253-65.

[19] Desbarats, A. J., Logan, C. E., Hinton, M. J., and Sharpe, D. R. 2002. "On the Kriging of the Water Table Elevations Using Collateral Information from a Digital Elevation Model." Journal of Hydrology 255 (1-4): 25-38.

[20] Finke, P. A., Brus, D. J., Bierkens, M. F. P., Hoogland, J., Knotters, M., and De Vries, F. 2004. "Mapping Groundwater Dynamics Using Multiple Sources of Exhaustive High Resolution Data." Geoderma 123 (1-2): 23-39.

[21] Rivoirard, J. 2002. "On the Structural Link between Variables in Kriging with External Drift." Mathematical Geology 34 (7): 797-808.

[22] Lloyd, C. D. 2005. "Assessing the Effect of Integrating Elevation Data into the Estimation of Monthly Precipitation in Great Britain." Journal of Hydrology 308 (1-4): 128-50.

[23] Hengl, T., Heuvelink, G. B. M., and Rossiter, D. G. 2007. "About Regression-Kriging: from Equations to Case Studies." Computers \& Geosciences 33: 1301-15.

[24] Fotheringham, A. S., Brunsdon, C., and Charlton, M. 2002. Geographically Weighted Regression: the Analysis of Spatially Varying Relationships. John Wiley \& Sons.

[25] Shi, H., Laurent, E. J., LeBouton, J., Racevskis, L., Hall, K. R., and Donovan M. 2006. "Local Spatial Modeling of White-Tailed Deer Distribution." Ecol Model 190: 171-89.

[26] Farrow, A., Larrea, C., Hyman, G., and Lema, G. 2005. "Exploring the Spatial Variation of Food Poverty in
Ecuador." Food Policy 30: 510-31.

[27] Yu, D. L. 2006. "Spatially Varying Development Mechanisms in the Greater Beijing Area: A Geographically Weighted Regression İnvestigation." Annals of Regional Science 40: 173-90.

[28] Yu, D., and Wu, C. 2004. "Understanding Population Segregation from Landsat ETMş İmagery: A Geographically Weighted Regression Approach." GIScience \& Remote Sensing 41 (3): 187-206.

[29] Brunsdon, C., McClatchey, J., and Unwin, D. J. 2001. "Spatial Variations in the Average Rainfall-Altitude Relationship in Great Britain: an Approach Using Geographically Weighted Regression." International Journal of Climatology 21: 455-66.

[30] Gundogdu, I. B., Esen O. 2010. "The Importance Secondary Variables for Mapping of Meteorological Data." Presented at the 3rd International Conference on Cartography and GIS, Nessebar, Bulgaria.

[31] Okwuashi, O. 2014. "Gis-Based Simulation of Land Use Change." Applied Gis 10: 1-18.

[32] Taghipour, J. S., Malekmohammedi, B., and Mokhtari, H. 2014. "Application of Geographically Weighted Regression Model to Analysis Spatiotemporal Varying Relationship between Groundwater Quantity and Land Use Changes Case Study (Khanmirza, Iran)." Environmental Monitoring \& Assessment 186 (5): 123-36.

[33] Xu, S. G., Wu, C. Y., Wang, L., Gonsamo, A., Shen, Y., and Niu, Z. 2015. "A New Satellite-Based Monthly Precipitation Downscaling Algorithm with Non-stationary Relationship between Precipitation and Land Surface Characteristics." Remote Sensing of Environment 162: 119-40.

[34] Ogneva-Himmelberger, Yelena, Pearsall, Hamil, Raskhit, and Rahul. 2009. "Concrete Evidence \& Geographically Weighted Regression: A Regional Analysis of Wealth and the Land Cover in Massachusetts." Applied Geography 29: 478-87.

[35] Tu, J., and Xia, Z. G. 2008. "Examining Spatially Varying Relationships between Land Use and Water Quality Using Geographically Weighted Regression I: Model Design and Evaluation." Science of the Total Environment 407: 358-78.

[36] Wentz, E., A., Gober, P. 2007. "Determinants of Small-Area Water Consumption for the City of Phoenix, Arizona." Water Resource Manage 21: 1849-63.

[37] Johnston, K., Ver Hoef, J. M., Krivoruchko, K., and Lukas, N. 2003. Using ArcGis Geostatistical Analyst. ESRI. 